\title{
Molecular Politics, Wearables, and the Aretaic Shift in Biopolitical Governance
}

Peter Lindner (1)

Goethe University

\begin{abstract}
Since the publication of Nikolas Rose's 'The Politics of Life Itself' (200I) there has been vivid discussion about how biopolitical governance has changed over the last decades. This article uses what Rose terms 'molecular politics', a new socio-technical grip on the human body, as a contrasting background to ask anew his question 'What, then, of biopolitics today?' - albeit focusing not on advances in genetics, microbiology, and pharmaceutics, as he does, but on the rapid proliferation of wearables and other sensor-software gadgets. In both cases, new technologies providing information about the individual body are the common ground for governance and optimization, yet for the latter, the target is habits of moving, eating and drinking, sleeping, working and relaxing. The resulting profound differences are carved out along four lines: 'somatic identities' and a modified understanding of the body; the role of 'expert knowledge' compared to that of networks of peers and self-experimentation; the 'types of intervention' by which new technologies become effective in our everyday life; and the 'post-discipline character' of molecular biopolitics. It is argued that, taken together, these differences indicate a remarkable shift which could be termed aretaic: its focus is not 'life itself' but 'life as it is lived', and its modality are new everyday socio-technical entanglements and their more-than-human rationalities of (self-)governance.
\end{abstract}

\section{Keywords}

biopolitics, governmentality, mobile health, molecular politics, self-tracking, wearables

\section{Introduction}

Failing to discipline oneself is an everyday experience. We fail to quit smoking, cut down on our alcohol consumption, give more thought to what we eat, exercise regularly, waste less time on social media, get up 
earlier and sit correctly while working at our desks. We even fail to avoid stress and to get enough sleep, both of which should be pleasant and therefore comparatively simple tasks. The Behavioral Technology Group offers a solution to this, promising to make it easy for you to 'change your habits, change your life' (www.pavlok.com). It is called Pavlok, a wristband with sensors, Bluetooth connectivity and a battery that delivers an electric zap when the wearer fails to comply with the goals set. Pavlok can be paired with a computer to admonish the user when social media apps have been open for more than ten minutes. It can use Google Maps and geofencing to warn the wearer when approaching a place where people are smoking which they may be tempted to enter. Those who want to lose weight can pair Pavlok with a smart fridge and receive a zap when they open it after 9 p.m. Anyone worried about looking unapproachable can use a laptop camera and face recognition to save the perfect smile and be zapped when their facial expression is negative. One can even allow friends to send a zap via Facebook Messenger, for example if they 'dislike' the body weight one posted in the morning. 'Your brain', advertisements promise, 'automatically creates an aversion, pairing the zap with that habit', making it easy to lead a healthier and better life (www.pavlok. com/break-habit). Pavlok costs $\$ 179.99$ and had sold nearly 60,000 pieces by May 2017.

Our contemporary understanding of biopolitics is decisively influenced by Rose's classic paper, 'The Politics of Life Itself' (2001), and its conceptual grounding in Powers of Freedom (2004). Rose begins by emphasizing the historicity of biopolitics and its embeddedness in social, political, economic, and scientific developments, and provokingly asks the question 'What, then, of biopolitics today?' (Rose, 2001: 1). In what ways have scientific knowledge and technological advances changed the predominant modes of biopolitical governance and its objects, targets and instruments? In his response he identifies a threefold turn to what he calls 'risk politics', 'molecular politics', and 'ethopolitics' (see Rose, 2007, for detailed elaboration). But this answer is necessarily only ever a preliminary one and the question never ceases to be current given the rapid changes in the sociotechnical fields in which it is grounded.

What, then, of biopolitics today with regard to the latest generation of mobile sensor-software technologies ('wearables'), of which Pavlok stands as an emblematic example? What about sleep trackers, which recommend the best times to go to bed and get up? Foodanalysing apps which make use of the Smartphone camera to encourage better nutrition and are part of the huge industry promoting the perfect (gendered) body? What about fitness trackers that set the standards for 'normal' activity levels and remind the wearer to fulfil the daily goal of 10,000 steps? Combined heart-rate and stress 
monitors which warn of the approach of critical thresholds and redefine the way we experience socio-spatial situations and interactions? Do these technologies stand for yet another biopolitical turn, as Schüll (2016) contends - perhaps even a 'milestone in the history of the modern subject', as Abend and Fuchs (2016: 15) put it? Should this turn still be called biopolitical or does it mark the emergence of a new field of (self-)governance for which an adequate depiction is still to be found? ${ }^{2}$

In what follows I argue that mobile sensor-software technologies are triggering a shift which eludes conventional understanding of contemporary biopolitics, from the body and 'life itself' (Rose, 2001: 20-2; Rabinow and Rose, 2006) to body-behaviour and 'life as it is lived'. This represents a new and unlooked-for convergence between the two great Foucauldian themes of biopolitics and of self-care. The notion of 'aretaic biopolitics', referring to the ancient concept of arete, which relates to situated practices leading to social acceptance and success, is proposed to capture this change. In particular, I focus on the various ways in which wearable technologies mediate between self, body-behaviour, and communities, using Rose's $(2001,2004,2007)$ intriguing analysis as a contrasting background against which I carve out continuities and ruptures in four dimensions: 'somatic vs. behavioural identities'; the role of 'expert knowledge'; the 'types of intervention'; and the 'discipline vs. post-discipline character'.

This article is based on a heterogeneous corpus of empirical material: first, participant observation at wearable technology conferences, pitches for wearable technology start-ups, and health company meetups in the cities of Berlin, Munich, Nuremberg and Cologne; second, extensive analysis of documents published or made available by the different stakeholders in the field of wearable technologies; and third, interviews with various experts ranging from company founders, software developers, and consultants to representatives responsible for e-health in private companies such as German Telekom and Germany's Commerzbank, and in the German Ministry of Health. ${ }^{3}$ It starts with a brief section outlining the social and economic pervasiveness of mobile sensor-software technologies which has - with some notable exceptions; see Ruckenstein and Schüll (2017) for a concise overview of the current debate - gone widely unnoticed by scholars of biopolitics in spite of the fact that some have already argued that we are witnessing the emergence of a 'sensor society' (Andrejevic and Burdon, 2015). The main part of the paper discusses the peculiarities of aretaic biopolitics in the four dimensions mentioned above. These are summarized in the conclusion as representing a different art of governing one's own life which is increasingly becoming established in parallel to Rose's 'politics of life itself'. 


\section{Wearables: Cyborgian Utopia, the Emerging Market, and the Health-Care Promise}

The considerable hype accompanying wearable technologies is rooted in the vision of transcending the limitations of the standard five (actually nine) human senses by ever-smaller and less conspicuous mobile sensors. As one of the speakers at the WT | Wearable Technologies Conference in Munich 2017 put it, 'the only thing limiting the potential of micro-sensors is our creativity' (author's field note). Combined with user interfaces, network connectivity and algorithmic big-data analysis, they promise to allow the continuous monitoring of bodily conditions, functions, and processes such as heart rate, blood pressure, body temperature, oxygen saturation, sleeping cycles, respiration and breathing noises, skin conductivity, blood circulation, glucose level, body-fat percentage, etc. Integrated into smartphones, watches, wristbands, belts, spectacles, contact lenses, hearing aids, toothbrushes, medical patches, the soles of footwear or simply clothing, they pave the way for entirely new forms of body surveillance, control, and optimization. The terminology in this quickly-growing sector is still in flux, but 'wearables' is increasingly used as a fuzzy umbrella term for all kinds of mobile sensor-software technologies that can be carried close to the body for self-tracking during everyday activities, deliver transmittable data about body parameters in digital format, and are applied in the four overlapping fields of health, wellness, sports and lifestyle (for slightly differing definitions see Bermingham-McDonogh, 2015: 6; Lupton, 2016a: 10-12; Mann, 2014; Office of the Privacy Commissioner of Canada, 2014: 2; Schüll, 2016). For a more detailed analysis of user practices it would be necessary to differentiate within this general category of 'wearables', but with regard to their biopolitical implications, their commonalities and common effects can serve as the vantage point.

Yet the hype around wearables is fuelled not only by the cyborgian utopia of sensor-based new human-body and human-environment relations but also by the very mundane forecast of an enormous emerging economy. PricewaterhouseCoopers (2015: 20) estimates that the worth of the wearables market in Europe alone will reach $€ 9.2$ billion in 2018, and the global outlook for 2020 is between US\$50 and 60 billion (Schröder, 2015: 60; Terry, 2015: 1429). The annual growth rate of 25 to 32 percent (PricewaterhouseCoopers, 2015: 20; MarketsAndMarkets, 2015 ) is attracting a multitude of new investors and start-ups on the one hand, and on the other is leading to fierce competition among the big players Apple (Apple HealthKit), Google (GoogleFit), and Samsung (ARTIK) for standards and platforms. It is estimated that, in 2018, 250 million such gadgets will be circulating worldwide (CCS Insight, 2014), and as of summer 2016 about 260,000 apps were available which had been downloaded 3.2 billion times from the major app 
stores (Research2Guidance, 2016: 8). The European Union calculates potential annual savings in the health sector of around $€ 100$ billion (Sharon, 2017: 100), so it is not surprising that since 2015 Germany has had a national E-Health Act scheduling the roll-out of a digital infrastructure which allows uploading from wearable devices to one's personal health account since 2018 (Bundesministerium für Gesundheit, 2017). Health insurance companies are beginning to economize physical behaviour by offering what they call Pay-As-You-Live (PAYL) contracts based on individualized instalments for customers who are willing to use tracking technologies and grant them access to their profiles, and big employers such as, for instance, British Petroleum are subsidizing fitness trackers for their employees. Taken together, these developments signal that an influential multi-stakeholder network is taking shape that connects users, manufacturers, investors and consultants, as well as firms offering integrated B2B solutions, corporations implementing wearablebased health-care systems, health insurance companies, physicians and state regulators.

Wearables, however, cannot be attributed to one specific social domain alone. Health plays a crucial role insofar as so-called 'lifestyle diseases' or 'non-communicable diseases' have come to the centre of public interest and political engagement in recent years (World Health Organization, 2013, 2014, 2015). They are now seen as the 'epidemics of the 21st century' (Milani et al., 2016: 582), a 'much greater public health threat than any other epidemic known to man', as the lead author of a WHO study puts it (New York Daily News, 2015) since infectious diseases have - at least in the Global North - lost their menace. Such problematization on the one hand and availability of new technologies on the other dovetail to create a giant new field of intervention and governance, which is backed by a more general shift from cure to prevention, often labelled 'New Public Health' (Larsen, 2011: 201; see also Little, 2015; Swan, 2012). Against this background the hype around mobile health (mHealth) becomes understandable: lifestyle diseases are attributed to habits and everyday behaviour such as smoking, drinking, poor nutrition, too little daily exercise, posture while working, sleep disorders, etc., and therefore require exactly what wearables offer, namely permanent monitoring, individualized recommendations, and even immediate feedback (optic, acoustic, haptic, electric). But to single out health as the domain with which wearable technologies are to be associated would be deeply misleading. Rather, the social meaning of 'health' itself is recast in this context, broadened and applied to better performance at work, optimized athletic ability, personal choices about nutrition, general physical behaviour, or even, in the most comprehensive sense, as a nebulous normative label for leading a good life.

At first glance, Rose's $(2001,2007)$ arguments appear to be a good fit for all three of these faces of wearable technologies - the cyborgian 
utopia of transcending the limitations of the human senses, the marketdriven impetus, and the promised potential for thwarting diseases. Yet as Schüll convincingly argues, it is "worth pausing to ask what might be distinctive about this emerging vision for health' (and the general conduct of life). Self-tracking, she stresses, is not about the molecularization of biopower but about 'datafication', and the 'self as database' should therefore be seen as a toehold for a form of 'governance by micronudge' which must be understood on its own terms and not as 'another illustration of the contemporary molecularization of biopower' (Schüll, 2016: 324-8).

\section{From Life Itself to Life as it is Lived}

Rose's work might be seen as the 'dominant story' (Braun, 2007: 7) about the technologically-induced enhancement of life and its social consequences, but it is by no means the only one. To name but a few other influential contributions, 'biosociality' and 'biosociety', as one strand of thinking had already been introduced in the 1990s by Rabinow (1992), to be further elaborated with regard to political rights (see Wehling, 2011, for an overview) and new technologies (Franklin, 2000; Franklin and Roberts, 2006). The question of 'biovalue' was raised by Waldby (2000) and Waldby and Mitchell (2006) and linked to a decidedly political-economy approach by Cooper (2008), while Rose's own interest in recent years has shifted from genetics and microbiology to representations of life and the 'neuromolecular gaze' (Rose and Abi-Rached, 2013).

All of these 'stories' are very much occupied with advances in genetics, microbiology, and pharmaceutics. Critical interventions do of course exist (Blencowe, 2012; Hannah, 2011; Ojakangas, 2005), yet they question the use of 'biopolitics' on conceptual grounds rather than with respect to new technologies and modes of intervention. Sensor-software devices, however, and their embeddedness in everyday routines and continuous use surreptitiously induce a significant shift from life itself to the (self-)governance of body-behaviour - 'life as it is lived'. This shift could be called 'aretaic', referring to the ancient concept of arete, which relates to a way of life that aims for practical excellence and is pursued differently in different fields by building on behaviour, bodily strength, and knowledge. Arete is therefore a kind of virtue and excellence that, although normatively substantiated, is not rooted in transcendental, universal categories as 'life' but is based on a shared understanding of what is good for a human being, on practices and role models that guarantee social recognition and success (MacIntyre, 2007). ${ }^{4}$ Body and everyday behaviour are both subject to arete, resembling the contemporary approach of disciplining behaviour to optimize the body and using body data to optimize behaviour. And as arete has always been bound 
to social contexts, this mutual relationship between body and behaviour is not a closed but a situated, relational, and open one.

Much like the preceding turn to life itself, this aretaic shift to life as it is lived implies considerably more than a mere change of instruments and targets: it draws on a new corpus of knowledge and brings about a different understanding of human life; it goes along with the emergence of new markets for devices, apps, and services, in this way conceding a new role in individual and public health to private companies seeking to make a profit; it is embedded in a reconfiguration of power, legitimacy, and responsibility via the attribution of new roles to networks of peers, experts, doctors, and individuals; finally, it is accompanied by a peculiar ethics of leading a healthy life as well as a new kind of somatization of identity. Environmental variables ranging from the food we eat and the chairs on which we sit to the air we breathe and the interactions in which we are involved become the new setting for biopolitical interventions. It is this broader perspective of a newly-emerging field of socio-technical (self-)governance that the micro-focused literature on wearable technologies quoted in the preceding section, with its interest in human-gadget and human-data relations, subjectification and optimization, rarely addresses. What is predominantly understood as biopolitics, namely the government of bodies and populations, is now merging with selfcare for body-behaviour and the obligation to lead a normatively good life - a convergence which Foucault, widely unnoticed, already had in mind when widening the objective of biopolitics from zoé (physical being) to bios (moral and political being; see Lemke, 2011).

Aretaic biopolitics differs from the (biological) politics of life itself in yet another way. It requires a new kind of scopic regime for body-behaviour, established by mobile sensor-software technologies, permanently working and easily accessible via smart interfaces. Like the mirrored markets and screens which were the subject of Knorr-Cetina's (2005b) classic inquiries, the smart devices of aretaic biopolitics erect an 'epistemological world' (Knorr-Cetina, 2005b: 129) around mirrored bodies. It is this world in which the normative stance that characterizes any kind of virtue is inextricably embedded - what used to be social standards and control in the ancient arete are now socio-technically distributed: the visualization of body data on screens goes hand in hand with optic, acoustic, and haptic 'callings' for normatively adequate reactions (Isin and Ruppert, 2015: 77, 79). Software programmers and their expert advisers from the fields of health, sports, wellness, and cosmetics, but also public health administrations and regulators, health insurance companies, and peer-users, leave their imprints on this 'world' by setting the standards for good and bad, right and wrong; standards which unfold always and only in tight entanglement with the technologies at hand and the ways they are used in practice. 
In what follows, the emerging contours of this biopolitical shift to body-behaviour are characterized in four dimensions: 'somatic vs. behavioural identities'; the role of 'expert knowledge'; 'types of intervention'; and the 'discipline vs. post-discipline character'.

\section{Beyond Somatic Identities}

The word 'soma' is of course omnipresent in the field of wearables - not only in the names of companies such as Soma Analytics (www.somaanalytics.com) but also more broadly as the pivotal point of reference to what is measured and analysed. ${ }^{5}$ Yet as 'mirroring devices', wearables do not represent so much as define the properties of the body, and in this respect could even be called 'a-representational' (Knorr-Cetina, 2005a: 221). For example, the BitBite app promises to facilitate a healthier life by monitoring eating patterns and analysing chewing sounds via microphones available in off-the-shelf headsets. The advertisement says: 'BitBite knows when, where, what and how the user is eating. Analysis of this data allows BitBite to send real-time dietary advice on how to eat healthier' (www.thebitbite.com). 'Eating pattern' here is a newly-defined parameter which depends on the combination of the sensor, big-data storage and algorithmic analysis (similarly, see the smart fork, HAPIfork, at www.hapi.com). It is a digitally-produced soma-artefact, a specific kind of 'data derivative' (Amoore, 2011) presented to the user not as neutral binary information but translated into a visual representation on a smartphone screen and loaded with normative guidance.

The 'somatic' in this example is different to Rose's understanding of the term, which gave rise to disputes about life itself. And BitBite is no exception: wearables record users' locations and environmental attributes such as a possibly harmful level of noise, the number of steps taken and body movements more generally, sounds and the electric parameters of the skin, the activities of organs and the chemical properties of the body. Some of this data may intuitively be associated with conventional understanding of the body proper; others, such as the sound of teeth chewing or sleep cycles, less so, and the number of steps walked during a day, for example, is clearly not a body parameter. What is measured in the realm of wearable technologies is so heterogeneous that there are good reasons not to use a single identifier that presumes some degree of internal coherence. But commonalities do indeed exist - they are rooted, somewhat paradoxically, less in what is measured and labelled as 'body parameters' than in the technologies themselves, in what is doing the measuring, how the measuring is done, and the way in which this becomes an everyday practice.

At first glance, this shift from the sensed body to a body brought about by the algorithmic work of sensor-software technologies resembles the previous shift from the clinical gaze on bodies (Foucault, 1972; cf. 
Philo, 2000) to a molecular understanding of life. Both seem fairly similar, insofar as they mark the transgression of what is visible or sensible, respectively, as the living human body, and both depend on new knowledge and technologies. But they are not. Rose himself gives some hints for critical reflection:

Unlike these uses of robotics and computing, which seem to make the human being less biological, the new molecular enhancement technologies do not attempt to hybridize the body with mechanical equipment but to transform it at the organic level, to reshape vitality from the inside: in the process the human becomes, not less biological, but all the more biological. (Rose, 2007: 20, emphasis in original)

In contrast, the body brought to life by wearable technologies is less biologically defined than it might seem; rather, it is a relational, context-dependent 'enactment' of the body. This of course is also the red thread running through Mol's (2002) Body Multiple, and a lot can be learned from this book to better understand the relationship between wearables, bodies and practices. As in the case of one of Mol's (2002: 22) respondents, Mrs. Tilstra, whose disease is only enacted in the consulting room although the pain in her leg was present before, the body parameter 'eating pattern', combining speed, force, and duration registered using sound as the indicator, is only enacted using BitBite. But enactment in the field of sensor-software technologies, as compared to Mol's hospital, acquires a different twist. It is about the relationship between person and data (Grew and Svendsen, 2017), which is established in two separate settings: first, in the calculative space of software programming, where algorithms produce real-time representations of bodily processes based on sensor data, and second, in the realm of the practices of users who read these representations and modify their bodybehaviour accordingly. While this makes the body the centre of attention and revalues its importance in identity formation, it surely does not make the human 'all the more biological' in Rose's (2007: 20) sense.

In the double process of enactment, raw data is charged with normative meaning and affect by those translating it into representations as well as by users relating it to their individual bodily behaviour (Cohn, 2010; Edwards et al., 2010). From the mundane perspective of the marketing divisions of private companies seeking to sell their devices and apps, this is crucial (Ledger and Endeavour Partners, 2016: 9). Only when potential customers are convinced that the data produced by wearables is highly relevant to them, to their health, to their efficiency at work or to their sleep 'efficiency', do they begin to spend money. It isn't the technology itself but making it significant to customers that is the biggest challenge for producers - it's all about 'getting people to use the damn thing, so 
that it becomes part of their lifestyle', as the Executive Vice President and Chief Medical Officer of a big insurance company put it (Schüll, 2016: $323)$. For that, data has to be turned into information with a normative connotation, a prompt to the user to improve, which usually depends heavily on how it is translated into visualizations and feedback - with alerting or calming colours, haptic and acoustic signals, benchmarks, comparison to averages, etc. Reacting to these representations means reworking one's body parameters, and in that way performing a modified enactment that transcends the body as 'life itself'.

From a biopolitical perspective this requires a critical take on the often-cited 'data doubles' (Lomborg and Frandsen, 2016; Lupton, 2014; Missomelius, 2016) produced by wearable technologies: these are not really 'doubles' - digital representations of bodies via numbers and visualizations - but they are related to bodies in a reflexive way and make them cyborgs (Lupton, 2012). As digitally-produced representations they supplement the experiences of the human senses, with which they have more in common than it might seem. Both involve the same difficult task of understanding what we can learn from what we 'sense' about our bodies - even a presumably natural feeling such as pain is often difficult to locate in the body, and interpreting it is more difficult still ('What is this feeling telling me about my body?'), and the same is true of sensor data. In an empirical study Ruckenstein (2014) shows convincingly that individuals reflect critically on their body data, presented to them as graphs and numbers, to make sense of it, but also how deeply emotional their attachment to this data can become - precisely because it is not understood as merely an external double.

Some embrace the data-based informational self as a means of liberation from biologically-fixed identity markers and as a "performative enactment' which transforms the 'passive body of the pre-digital age', not according to technologies of power but following new emancipatory rationalities (Belliger and Krieger, 2016: 25). But the new ethics of selfcare and of leading a good life are pre-set by the way body-behaviour parameters are normatively represented as good, average or bad, and therefore they establish a new kind of aretaic biopower; gender-related standards for the ideal body offer a striking example here (Sanders, 2017). Yet a degree of openness and contingency is contained in the double process of enactment, and making sense of body data is clearly a more-than-somatic endeavour.

\section{Beyond Expert Knowledge}

Molecular politics, as defined by Rose, implies a shift from the state as the omnipresent governing entity to networks of 'experts of life itself' (Rose, 2007: 27, cf. 2004: 74) - scientists, physicians, counsellors, and other professionals. Yet in the currently emerging field of mHealth the 
state is even less present than in molecular politics, which triggered a vast corpus of new laws and regulations, and the foundation of ethical commissions advising legislative bodies. The users of wearables are hardly going to cite the potential of this new technology in claims against the state for better healthcare, such as those that Rose (2007: 25) reports to genetic support groups, and so sensor-software technologies seem to continue or even enhance the decentring of biopolitical power. Yet, beyond the continuity in some areas, change is taking place in others. It relates to knowledge production as well as to the relationality of power and networks as they are held together by the various stakeholders of wearable technologies.

The Virgin Pulse Global Challenge (www.globalchallenge.virginpulse. com) serves as a good example for this change. Each year, hundreds of thousands of employees in more than 180 countries register in teams of seven, receive fitness trackers and participate in a competition to reach health-related goals by tracking their physical activity and uploading their data onto the company's servers. 'The experience is brought to life with our award-winning website and smartphone apps, weekly personalized emails, community message boards, live team leader boards', says the promotion (www.globalchallenge.virginpulse.com/programoverview). This 'award-winning website' contains a map of the globe visualizing the achievements of other teams around the world ('Ken's team in Singapore reaches 7 million steps') as well as various comparative statistics. In addition, the more than 5500 companies participating receive aggregated health and activity reports on their employees.

The decisive point made by this promotion might easily be overlooked: the experience of health and the body is one which is 'brought to life' by comparison and competition. The point of reference by which to qualify the self and one's own body is not an expert interpreting individual body data and recommending treatment, but networks of others who share data and experiences. The technologically-mediated communication and exchange at the heart of this process create attachment, and therefore most producers of wearables pay a lot of attention to social media options or set up their own platforms for sharing and community building. 'Tech for your connected self' is the slogan of the prominent webpage 'Wareable', which also announces the 'social age of wearable tech' (www.wareable.com/wearable-tech/the-social-age-of-wearable-techbeyond-the-quantified-self); and the Quantified Self movement, with more than 100 groups in 34 countries, 'actively encourages and structures the sharing of personal health and wellness data' (Barta and Neff, 2015: 519), emphasizing 'user communities' and the 'spirit of friendship' (www. quantifiedself.com/about). Even the often-quoted 'sousveillance' (mutual surveillance from below: Bailey and Kerr, 2007: 131; Karanasiou and Kang, 2016: 124; Lupton, 2016b: 103; Mann et al., 2003: 331) is an expression of the peer-group character of self-tracking. Whereas the 
individual visit of a physician used to be indicative of molecular politics, today the purchase of a gadget that visualizes norms derived from mass data or the setting up of a web account offering contact with a community of users are entrance points to a different kind of body politics.

During the process of exchange and comparison, data is classified and a joint understanding of averages and standards emerges which easily becomes naturalized and turns into an 'inscription of moral rules' (Abend and Fuchs, 2016: 14) that provides benchmarks against which to assess one's own achievements and which guides the work on one's own bodily behaviour. The already-described friendly-face function of Pavlok is surely one of the most impressive examples in this respect, as it immediately demonstrates how normative expectations of others - or to be more precise, anticipated expectations - become inscribed within one's own body by the adoption of a smart facial expression. But 'pplkpr', which is at the same time a provocative art project and an app that 'monitors your physical and emotional response to the people around you, and optimizes your social life accordingly' using heart-rate variability as an indicator, is as striking (www.pplkpr.com). It points to a further important quality of the relationality of the newly-emerging self-tracking networks which is even more clearly expressed in some other sensorbased apps: this relationality is not limited to communities of users sharing their data but includes the environment in a much broader sense (Pink and Fors, 2017). Spatial and material settings, too, contribute to how users make sense of body data, as in many cases locational and environmental parameters are variables for the algorithmic processing and the visualization of sensor data.

To state that wearable technologies position the subject in relation to other users and the environment is not to say that experts are entirely absent, but their position in the networks is different from the case of molecular politics. Users themselves contribute to the development of the technologies by experimenting with their bodily behaviour and sharing the results of individual trial-and-error knowledge production; they become 'experts of practice' and 'produsers' (Bruns, 2008: 101-36). The traditional type of expert, in contrast, now remains largely behind the scene or acts as a 'moderator', as Steinmann (2017) puts it. They may be directly involved because some apps recommend visiting a doctor when indicated, and others, for instance many anti-depression apps, even provide for a set amount of time for personal communication with a specialist. But more importantly, experts and professionals set the benchmarks and goals that are part of nearly any sensor-based app, and they perform the task of pre-interpreting the data, a step that is crucial in so many respects. The omnipresent yet rather contingent 10,000-steps-a-day target is a perfect example of how performative these benchmarks can become (Fujieda et al., 2006; Tudor-Locke et al., 2008, 2011). 
Wearable-user networks are often characterized as 'heterarchic' (Barta and Neff, 2015: 524-5; see also Stark, 2009: 5), and the knowledge they circulate as 'empowering' because it may shift the balance of power between expert and layman, doctor and patient, user and producer (European Commission, 2014: 5; see also deBronkart, 2014). The new 'citizen health' (Fox, 2017: 136) is sometimes celebrated as a sovereign subject who knows her rights and opportunities, and the 'informational self' (Belliger and Krieger, 2016: 33) might make it possible to de-essentialize categories such as gender from 'corporeal and societal forms and determinations' (Cheney-Lippold, 2011: 170). My take on this is much more cautious, as many of these hopes still lack empirical evidence. But it seems clear that the role of experts, and as a result the relational position of users, has changed, and that the ethics of self-care as a crucial element of the aretaic shift is establishing a new kind of biopower which receives its dynamics not least from comparison and competition with the mass of others using the same technologies.

\section{Beyond Intervention in Life Itself}

The idea of emancipated citizen health made possible by wearable technologies is at the same time a hint of another change in the way the individual is supposed to relate to her body. In molecular politics, advances in science and technology have opened up multifarious options for a new grip on life, with a vast array of 'somatic experts' positioning themselves as intermediaries between the new body knowledge and its application - as addiction, sex, family, and reproduction counsellors; psychological, speech, and art therapists; health visitors; nutritionists; dieticians; remedial gymnasts, etc. (Rose, 2007: 28). They have in common the fact that their work relies on more or less discrete interventions, diagnoses, and subsequent prescriptions: first there is any kind of assessment, an anamnesis, an examination, a genetic screening, a laboratory analysis, an inventory conversation; next follow recommendations and instructions, a recipe, a treatment, a medication, a nutrition plan, an exercise scheme, a therapy or a schedule for therapeutic and consultation sessions. Engaging with biopolitics in this sense involves an interruption of the everyday - it requires the often-difficult decision to actively take the first step and consult a specialist, and it usually, although not always, is bound to a certain time horizon after which the intervention (successfully) ends. This comes most clearly to the fore in the wish to become a parent and the paradigmatic case of reproductive technologies.

But occasionally an overtone of something beyond intervention, diagnosis, prescription, and treatment is present in Rose's (2007: 131, 144) writings on 'biological citizenship' and 'biosociality' which resembles aretaic rather than molecular politics. It is, however, more indicated than really elaborated, and is presented as a part of molecular politics 
rather than as a new field. In the respective passages Rose writes more about routines than about 'hope' and 'acts of choice' (2007: 135, 154), more about behaviour than about the body, and more about sociotechnical embeddedness in everyday activities (sleeping, eating, working, walking, etc.; Lomborg and Frandsen, 2016) than about discrete interventions. This constitutes the fundament of what is meant today when responsiblized citizen health is invoked in relation to wearable technologies: the vision of permanently monitoring bodily functions, movements, and behaviour as a new way to reflect on habits, as a lifestyle which crucially rests on new knowledge about individual wellbeing and the corresponding responsibility for leading a healthier life. 'Continual accompaniment and reminders' via sensor-software technologies and visualized data analysis rather than 'intervention' is the basic principle here.

To make this not only possible but also acceptable for users, the lowthreshold character of wearables, as compared to the technologies of molecular politics, is decisive: they are relatively cheap, easily accessible, designed to be user-friendly, and present information and feedback as simply as possible. Increasingly, they are becoming smoothly embedded in the working environments of big employers such as British Petroleum, which subsidizes Fitbit wristbands for its employees (Mämecke, 2016; Moore, 2017, 2018; cf. also Halford et al., 2010); others enrol them in mHealth programs such as the one offered by the Virgin Pulse Global Challenge (British Petroleum, 2016; National Business Group on Health/ Xerox Human Resources Services, 2016; www.globalchallenge.virginpulse.com). Smartwatches are emblematic of this seamless integration, which the term 'wearables' captures: the 'container', the watch, is a traditional everyday object, familiar to everybody, and barely changes its shape - however, now it fulfils entirely new functions: for instance, the latest version of the Apple Watch records cardiograms, warns of toonoisy environments, and there are plans for it to become a tool for the diagnosis of hypertonia and diabetes in the long run (Cook and Cramer, 2015). It is this embedded character of the technologies that creates commonalities regarding their governmental implications, rather than a common target ('life itself', as Rose identifies it): a new unobtrusive 'scopic regime' established in everyday life and inciting new 'scopic valuations' of body-behaviour (Dobeson, 2016).

The mentioned intuitive and normative visualizations, as in Apple's global 'Close the Rings' campaign, where colourful rings on the smartwatch indicate that daily health targets have been reached, are techniques used to create a feeling of responsibility among users and in that way foster continuity of use. These expressive representations can be seen as a peculiar example of what Isin and Ruppert (2015), in their work on digital citizenship, term 'callings': demands articulated by new digital technologies to 'perform ourselves ... through actions', 'to be open and 
responsible', and to become 'subjects through the play of obedience, submission, and subversion' (Isin and Ruppert, 2015: 77, 79; emphasis in original). These callings, or 'interpellations' (Butler, 1993: 120ff), which always bear the risk of failure, are increasingly reinforced by economic incentives on a hitherto unknown scale. 'Changes in benefit program design increasingly require individuals to take personal responsibility for their wellbeing', states Karen Marlo, vice president of the National Business Group on Health (National Business Group on Health, 2016), for instance. What she is pointing to is the still experimental but rapidly growing market for pay-as-you-live health insurance plans, which 'can't be stopped any more' according to most insurance company representatives (Kaspar, 2015; see also Ernst \& Young, 2015). These require customers to permanently use their wearables and grant the insurer access to the recorded data so that tariffs can be continually adapted according to their individual lifestyle. Here, leading a 'responsible life' means saving money. And at the same time, it implies a shift from a right to health to the duty to stay healthy (Sanders, 2017).

Yet neither is the healthy body, itself already a broad denominator covering sports and fitness as well as cosmetics and body aesthetics, the sole target for improvement, nor can the aims be clearly identified. 'Optimization' - the most common general term usually associated with self-tracking and wearable technologies (Meißner, 2016) - includes not only physical health, bodily performance and work efficiency but also anything that is regarded as part of personal wellbeing. Muse (www. choosemuse.com) is a good example of how broadly this has to be understood and the paradoxical forms this optimization can take: it is a brainsensing headband that registers brain activity during meditation sessions, sends the data via Bluetooth to a smartphone, and translates it into graphs and charts for evaluation. Muse clearly transcends established categorizations, bringing together an exemplary qualitative, non-competitive mental experience such as meditation with quantified visual representations and the clear intention to 'improve performance', set 'milestones', 'measure progress' and receive 'rewards', as the advertising proclaims (www.choosemuse.com). Mood-monitoring apps are another example of continuity and the transcendence of the body and health as targets, but an example that also indicates that quantification is a frequent but not necessary precondition for everyday control and optimization (Belli, 2016; Davies, 2016; Pritz, 2016).

The shift from discretionary intervention to everyday continuous selfmonitoring, but even more its health-transgressing lifestyle character, make aretaic biopolitics different. It refers to a shared understanding of what leading a good life means and implies an ethics of self-care, both of which gain shape within the pre-set socio-technical framework of new sensor-software technologies on the one hand and the normative representation of new body data on the other. 


\section{Beyond Post-Discipline Biopolitics}

The advent of molecular politics seems to mark the beginning of a time in which self-optimization no longer entails self-discipline. '[U]nlike previous practices of self-improvement, which required exercise of the will, training over long periods, hardships and endurance', writes Rose (2007: 20-1), 'these new enhancement techniques can be acquired without much exertion.' Painkillers, anti-depression drugs, Viagra and contraceptive pills function independently of the individual will and control on which so many other technologies of the self rely, and the same is true of organ transplants, plastic surgery and genetic testing. Yet they still require "the active and responsible citizen' (Rose, 2007: 223), a subject willing to rationally monitor herself and consequently make decisions about improving her health.

Aretaic biopolitics established by sensor-software technologies is clearly different in this respect, yet the picture is complicated and not without contradictions. A first important characteristic is the fact that while self-discipline is not a significant issue here, neither is the postdiscipline promise of molecular politics. Rather, the effort of disciplining body-behaviour is shifted from individuals to their gadgets with their ability to deliver the right kind of information and feedback at the right time and set the right incentives in the right way, the already-mentioned Pavlok being one of the most extreme examples in this respect. This is not to say that self-discipline becomes entirely dispensable; yet what moves to the centre of interest now is the external framework guiding and supporting self-discipline. The analogy with behavioural economics' concept of 'nudging' (Thaler and Sunstein, 2008; cf. also Jones et al., 2013) is obvious, and so it is hardly surprising that a prominent health coach app calls itself Nudge (www.nudgecoach.com). Schüll (2016: 326) specifies wearable technologies as delivering 'micronudges' and Lupton (2016b: 107) explicitly uses 'persuasive computing' or 'pushed self-tracking' as equivalents to the 'nudge' in self-tracking environments.

This analogy is anything but accidental. It is the result of multifarious translations putting behavioural science knowledge - from economics as well as from psychology - to work in the incentive-cum-feedback systems of wearable technologies. The field of persuasive computing or 'captology' (computer-aided persuasive technology) is indicative here; the term was invented by BJ Fogg, still one of the most prominent figures in the field, who works as a researcher at Stanford University and at the same time as a consultant specializing in mobile health projects. Many other experts at the intersection of scientific knowledge and product development are also intensely entangled with practitioner networks: Dustin DiTommaso, for instance, a well-known consultant and senior vice president of Behavior Change Design at mad*pow (www.madpow. 
com), is engaged with the global business accelerator network Startupbootcamp (www.startupbootcamp.org) and holds seminars for young entrepreneurs on how to implement 'theory-backed and evidence-based behaviour change techniques' (www.madpow.com/ / media/files/behavioralchange_2016_sales.ashx) in mobile health applications. At start-up meetings such as the global WT | Wearable Technologies Conference series, references to the tightening linkage between this peculiar corpus of knowledge and mHealth applications are omnipresent. Andrew Webb, for example, the Generali Group's Head of Products and the most prominent global player introducing PAYL health insurance schemes, depicted the company's lifestyle politics as 'underpinned by behavioural economics' (WT | Wearable Technologies Conference in Munich, 2017: author's field note).

Second, as paradoxical as it might sound, fun, joy and 'somaaesthetic experiences' (Shusterman, 2014) are introduced as the new substitute for or at least concomitants of self-discipline: 'Empower people to achieve their goals with minimum effort and maximum enjoyment' is the slogan of mad*pow (www.madpow.com/ /media/files/behavioralchange_2016_ sales.ashx). This represents a remarkable shift away from a rationalitybased to an emotional and affective approach to optimization. And it is perfectly conveyed by the fact that the guiding principle of the branch in recent years has become gamification (Fuchs et al., 2014) - a concept which sounds much more self-explanatory than it actually is. Video games and gambling environments serve as blueprints (Ruffino, 2016) because they successfully create the kind of affective and physical attunement (Ash, 2013) that app developers in the health sector are aiming fornot only to achieve sustainable health effects but also as a marketing model to create customer loyalty, as Schollas (2016) argues. The aim is to get the user in the 'machine zone' (Gekker, 2016: 114; cf. Schüll, 2014), an attitude of playfulness in which non-reflexive interaction with the gadget becomes a purpose in itself. Whether this playfulness is really about joy or more about the physical and emotional experience of immediate feedback and control is a contested question (Whitson, 2014). But it surely takes place in sophisticated choice architectures inspired by behavioural sciences and economics, and it is definitively geared to promote a healthy lifestyle (Munson et al., 2014; Schrape, 2014).

Third, although I have argued that the post-discipline potential of molecular politics does not extend to sensor-software technologies, some of them do carry a beyond-discipline promise, yet of a very different kind than the one Rose describes. To engage with the combination of choice architecture, playful attachment and immediate feedback loops surely requires some effort in the beginning. But once wearable technologies have become part of one's everyday life, it is assumed that the disciplinary work on bodily behaviour is replaced by new habits and ultimately by a new lifestyle. Changing habits and lifestyle might be 
hard, but clearly both notions carry the prospect that, with time, discipline will become unnecessary. Consultancy reports often fill many pages on how to reach this point (Ledger and Endeavour Partners, 2014), but the behavioural change aimed at here is based on routines and 'automaticity', and less on discipline (Munson et al., 2014: 600; cf. Gardner and Jenkins, 2016: 19). It is more appropriately described as a 'design practice' - the technical, aesthetic, and ethical formation of the self, based on sensor-generated body-behaviour data (Dyer, 2016: 161; Belliger and Krieger, 2016). To summarize, the power of aretaic biopolitics rests not only on the responsibilized, rational subject but also on the nonrational, emotionally-acting homo ludens.

\section{Conclusion: An Aretaic Shift in Biopolitical Governance}

Changes in biopolitical governance are messy developments. They gradually emerge out of 'often minor processes, of different origin and scattered location, which overlap, repeat, or imitate one another, support one another, distinguish themselves from one another according to their domain of application, converge and gradually produce the blueprint of a general method' (Foucault, 1995: 138). The biopolitical effects of the current spreading of sensor-software technologies are not dissimilar in this respect. They are brought about by a broad array of different gadgets which at first glance have little to do with one another. Private-sector players focusing on them - start-ups and the tech giants, insurance companies and employers in the manufacturing and the service sectors - follow distinct interests and rationalities. Users and consumers make them an integral part of their everyday life, but pursue diverse goals. State authorities begin to support them by prescribing general standards for the handling of medical data and by forcing hospitals and doctors to prepare for personal digital data transfer, as Germany's E-health Act does. Gradually, the 'clinical gaze', which has been replaced by a 'molecular gaze' over the last century, is being supplemented by a 'behavioural gaze'.

The picture is blurry, but it has gained contours over recent years. Next to a politics of life itself, a new politics of life as it is lived is taking shape which has its vantage point in the sphere of health and fitness, but proliferates into lifestyle and wellness, cosmetics and body aesthetics, work efficiency and a general 'government of life' (Lemke, 2011). It is different insofar as it retains the body as its point of reference yet defines it relationally, based on non-perceptible data derivatives (Amoore, 2011) of context-dependent body-behaviour. This politics still draws on expert knowledge but relies heavily on members of usernetworks comparing their experiences and on individual trial-and-error experimentation. It requires discretionary intervention on introduction, but is ultimately based on the everyday continuity of micro-technologies 
allowing for optimizations in rather different fields of life. Finally, inspired by the concept of nudging, it actually demands some kind of discipline, but promises to eventually replace discipline by bringing about a new body-subject shaped by technical, aesthetic, and ethical design practices. More than Rose's politics of life itself the new politics of life as it is lived embodies a convergence of what Foucault described as biopolitics on the one hand and care of the self on the other - possibly a convergence he would have dealt with in his unfinished book on technologies of the self.

To position this shift exclusively within the framework of an expanding neoliberal mode of governance would surely not go far enough; the contexts and aims in which sensor-software technologies are starting to be applied at the intersection of body and behaviour are too multifarious. And neither is it simply about health and a good life, as the advertisements never tire of emphasizing. The ancient Greek concept of arete might capture best what is entailed: a conduct of life aiming for practical excellence, to be pursued differently in different fields by building on behaviour, bodily strength, and knowledge. Whereas progress in microbiology, pharmaceutics and genetics has brought up the most fundamental questions about life itself, the aretaic shift calls for the relocation of the focus to everyday sociotechnical entanglements and their more-thanhuman mechanisms of behavioural regulation. The latter relate the 'injunction of having to know oneself' (Foucault, 1997: 226) increasingly to the digital self and make it a contemporary 'moral sentiment' in Fourcade's (2017: 666) sense. These entanglements need to be problematized all the more, as their proliferation progresses widely unnoticed by scholars of biopolitics and is underpinned by a general pretension of enabling a 'good life' that obscures the multiple rationalities of this new mode of (self-)governance.

\section{Acknowledgements}

I am grateful to the members of the 'Bios-Technologies-Society' research network, to Iris Dzudzek, Nanja Nagorny, Antje Schlottmann, Carolin Schurr, Alexander Vorbrugg, and especially to Natasha Dow Schüll and the anonymous reviewers for critical feedback on earlier drafts of this article.

\section{ORCID iD}

Peter Lindner (D) https://orcid.org/0000-0003-3056-8441

\section{Notes}

1. Some of these functions are not yet available on the market, but I was able to test them during an interview with the CEO of the Behavioral Technology Group in April 2017.

2. To answer this question would require a careful discussion of the existing concepts of biopolitics (of which Rose's is only one) and the Foucauldian 
analytics by which they were identified and characterized. Neither can be provided here for reasons of space. Suffice it to say that my take on these points follows Koopman (2014), who argues that Foucauldian analytics (e.g. archaeology, genealogy) are promising tools for better understanding the transformation of established or newly-emerging fields of governance but that they should be separated from concepts such as biopolitics. The latter are bound to specific historical and political constellations and characterized by unique socio-material assemblages, and hence must be used much more carefully than is often the case. The reason why I nevertheless use the notion of biopolitics in the context of wearables is that Foucault's use of 'bio' was never restricted to the somatic but included practices and the 'social' (Blencowe, 2012: 35).

3. All fieldwork was carried out as part of the ongoing research project 'Markets Coming Closer: Mobile Health, Wearable Technologies and the Economization of Bodily Behaviour'.

4. It was only with the sophists that the meaning of areté began to change until it became for Aristotle a virtue which 'is to be understood against the background of a teleological conception of man - a conception according to which human beings have a specific nature which determines their proper aims and goals' (Horton and Mendus, 1994: 6; see also Cürsgen, 2014; Kube, 1969; Stemmer, 1998).

5. I use the notion of 'representation' throughout this article in the specific sense of making sensor data perceivable by translating it into visualizations, acoustic signals, or haptic feedback.

\section{References}

Abend P and Fuchs M (2016) Introduction: The quantified self and statistical bodies. Digital Culture \& Society 2(1): 5-21.

Amoore L (2011) Data derivatives: On the emergence of a security risk calculus for our times. Theory, Culture \& Society 28(6): 24-43.

Andrejevic M and Burdon M (2015) Defining the sensor society. Television \& New Media 16(1): 19-36.

Ash J (2013) Technologies of captivation. Body \& Society 19(1): 27-51.

Bailey J and Kerr I (2007) Seizing control?: The experience capture experiments of Ringley \& Mann. Ethics and Information Technology 9: 129-139.

Barta K and Neff G (2015) Technologies for sharing: Lessons from quantified self about the political economy of platforms. Information, Communication \& Society 19(4): 518-531.

Belli J (2016) Unhappy? There's an app for that. Digital Culture \& Society 2(1): $89-103$.

Belliger A and Krieger D (2016) From quantified to qualified self. Digital Culture \& Society 2(1): 25-40.

Bermingham-McDonogh N (2015) The Data Science of the Quantified Self. Amsterdam: Vrije Universiteit Amsterdam.

Blencowe C (2012) Biopolitical Experience: Foucault, Power and Positive Critique. London: Palgrave Macmillan.

Braun B (2007) Biopolitics and the molecularization of life. Cultural Geographies 14(1): 6-28. 
British Petroleum (2016) BP LifeBenefits: BP Wellness Program. Available at: http://hr.bpglobal.com/LifeBenefits/Sites/Core/BP-Life-benefits/Employeebenefits-handbook/BP-Medical-Program/How-the-BP-Medical-Programworks/PPO-Options-(HealthPlus-and-Standard)-summary-char/BP-

Wellness-Program.aspx (accessed 17 August 2017).

Bruns A (2008) Blogs, Wikipedia, Second Life, and Beyond: From Production to Produsage. New York: Peter Lang.

Bundesministerium für Gesundheit (2017) Das E-Health Gesetz. Available at: www.bundesgesundheitsministerium.de/themen/krankenversicherung/ehealth-gesetz/e-health.html (accessed 14 July 2017).

Butler J (1993) Bodies that Matter: On the Discursive Limits of 'Sex'. New York/ London: Routledge.

CCS Insight (2014) Wearable Forecast. Summary. Available at: www.ccsinsight. com/press/company-news/1944-smartwatches-and-smart-bands-dominatefast-growing-wearables-market (accessed 31 May 2017).

Cheney-Lippold J (2011) A new algorithmic identity: Soft biopolitics and the modulation of control. Theory, Culture \& Society 28(6): 164-181.

Cohn S (2010) Picturing the brain inside, revealing the illness outside: A comparison of the different meanings attributed to brain scans by scientists and patients. In: Edwards J et al. (eds) Technologized Images, Technologized Bodies. New York: Berghahn Books.

Cook T and Cramer J (2015) Interview with Tim Cook. MadMoney, 12 March. Available at: www.cnbc.com/2015/03/12/apple-ceo-tim-cook-shocks-cramer. html (accessed 10 August 2017).

Cooper M (2008) Life as Surplus: Biotechnology and Capitalism in the Neoliberal Era. Seattle: University of Washington Press.

Cürsgen D (2014) Tugend/Bestform/Exzellenz (aretê). In: Schäfer C (ed.) Platon-Lexikon. Darmstadt: Wiss. Buchgesellschaft.

Davies W (2016) How are we now? Real-time mood-monitoring as valuation. Journal of Cultural Economy 10(1): 34-48.

DeBronkart D (2014) Lasst Patienten mithelfen. In: Belliger A and Krieger D (eds) Gesundheit 2.0: Das ePatienten-Handbuch. Bielefeld: Transcript.

Dobeson A (2016) Scopic valuations: How digital tracking technologies shape economic value. Economy and Society 45(3-4): 454-478.

Dyer J (2016) Quantified bodies. Digital Culture \& Society 2(1): 161-167.

Edwards J et al. (2010) Technologized images, technologized bodies. In: Edwards $\mathbf{J}$ et al. (eds) Technologized Images, Technologized Bodies. New York: Berghahn Books.

Ernst \& Young (2015) Introducing 'Pay As You Live' (PAYL) Insurance. Available at: www.ey.com/Publication/vwLUAssets/EY-introducing-pay-asyou-live-payl-insurance/\$FILE/EY-introducing-pay-as-you-live-payl-insurance.pdf (accessed 16 August 2017).

European Commission (2014) Green Paper on Mobile Health ('mHealth'). Brussels: European Commission.

Foucault M (1972) Birth of the Clinic: An Archaeology of the Clinical Gaze. London: Tavistock.

Foucault M (1995 [1975]) Discipline and Punish: The Birth of the Prison. New York: Vintage Books. 
Foucault M (1997 [1982]) Technologies of the self. In: Rabinow P (ed.) Essential Works of Foucault 1954-1984: Ethics. New York: New Press.

Fourcade M (2017) The fly and the cookie: Alignment and unhingement in 21stcentury capitalism. Socio-Economic Review 15(3): 661-678.

Fox N (2017) Personal health technologies, micropolitics and resistance: A new materialist analysis. Health 21(2): 136-153.

Franklin S (2000) Life itself: Global nature and the genetic imaginary. In: Franklin S et al. (eds) Global Nature, Global Culture. London: SAGE.

Franklin S and Roberts C (2006) Born and Made: An Ethnography of Preimplantation Genetic Diagnosis. Princeton: Princeton University Press.

Fuchs M et al. (2014) Rethinking Gamification. Lüneburg: Meson Press.

Fujieda Y et al. (2006) Walking 10,000 steps per day is effective to improve coronary risk factors among Japanese middle-aged men. Japanese Journal of Physical Sports Medicine 55: S37-S42.

Gardner P and Jenkins B (2016) Bodily intra-actions with biometric devices. Body \& Society 22(1): 3-30.

Gekker A (2016) Casual power: Understanding user interfaces through quantification. Digital Culture \& Society 2(1): 107-122.

Grew JC and Svendsen M (2017) Wireless heart patients and the quantified self. Body \& Society 23(1): 64-90.

Halford S et al. (2010) Getting the whole picture? Information, Communication \& Society 13(3): 442-465.

Hannah MG (2011) Biopower, life and left politics. Antipode 43(4): 1034-1055.

Horton J and Mendus S (1994) Alasdair MacIntyre: After virtue and after. In: Horton J and Mendus S (eds) After MacIntyre: Critical Perspectives on the Work of Alasdair MacIntyre. Cambridge: Polity Press.

Isin E and Ruppert E (2015) Being Digital Citizens. New York: Rowman \& Littlefield.

Jones R et al. (2013) Changing Behaviours: On the Rise of the Psychological State. Cheltenham: Edward Elgar.

Karanasiou AP and Kang S (2016) My quantified self, my FitBit and I. Digital Culture \& Society 2(1): 123-142.

Kaspar MM (2015) Pay-as-you-live nicht aufzuhalten. Versicherungswirtschaft heute, 26 October. Available at: http://versicherungswirtschaft-heute.de/vertrieb/pay-live-nicht-aufzuhalten (accessed 16 August 2017).

Knorr-Cetina K (2005a) Complex global microstructures: The new terrorist societies. Theory, Culture \& Society 22(5): 213-234.

Knorr-Cetina K (2005b) From pipes to scopes: The flow architecture of financial markets. In: Barry A and Slater D (eds) The Technological Economy. London/New York: Routledge.

Koopman C (2014) Michel Foucault's critical empiricism today: Concepts and analytics in the critique of biopower and infopower. In: Faubion JD (ed.) Foucault Now: Current Perspectives in Foucault Studies. Cambridge: Polity Press.

Kube J (1969) Techne und Arete: Sophistisches und platonisches Tugendwissen. Berlin: De Gruyter.

Larsen LT (2011) The birth of lifestyle politics: The biopolitical management of lifestyle diseases in the United States and Denmark. In: Bröckling U et al. 
(eds) Governmentality: Current Issues and Future Challenges. New York: Routledge.

Ledger D and Endeavour Partners (2014) Inside Wearables: How the Science of Human Behavior Change Offers the Secret to Long-Term Engagement. Cambridge, MA: Endeavour Partners.

Ledger D and Endeavour Partners (2016) Inside Wearables - Part 3: The Rocky Path Towards Personalized, Insightful Wearables. Cambridge, MA: Endeavour Partners.

Lemke T (2011) Beyond Foucault: From biopolitics to the government of life. In: Bröckling U et al. (eds) Governmentality: Current Issues and Future Challenges. New York: Routledge.

Little J (2015) Nature, wellbeing and the transformational self. The Geographical Journal 181(2): 121-128.

Lomborg S and Frandsen K (2016) Self-tracking as communication. Information, Communication \& Society 19(7): 1015-1027.

Lupton D (2012) M-health and health promotion: The digital cyborg and surveillance society. Social Theory \& Health 10(3): 229-244.

Lupton D (2014) Self-tracking cultures: Towards a sociology of personal informatics. In: Association for Computing Machinery (ed.) Proceedings of the 26th Australian Computer-Human Interaction Conference on Designing Futures: The Future of Design. Sydney.

Lupton D (2016a) The Quantified Self: A Sociology of Self-Tracking. Cambridge/Malden: Polity Press.

Lupton D (2016b) The diverse domains of quantified selves: Self-tracking modes and dataveillance. Economy and Society 45(1): 101-122.

MacIntyre A (2007 [1981]) After Virtue: A Study in Moral Theory. Notre Dame: University of Notre Dame Press.

Mämecke T (2016) Benchmarking the self: Kompetitive Selbstvermessung im betrieblichen Gesundheitsmanagement. In: Duttweiler S et al. (eds) Leben nach Zahlen: Self-Tracking als Optimierungsprojekt? Bielefeld: Transcript.

Mann S (2014) Wearable computing. In: Soegaard M and Dam RF (eds) The Encyclopedia of Human-Computer Interaction. Available at: www.interactiondesign.org/literature/book/the-encyclopedia-of-human-computer-interaction2nd-ed (accessed 31 May 2017).

Mann S et al. (2003) Sousveillance: Inventing and using wearable computing devices for data collection in surveillance environments. Surveillance \& Society 1(3): 331-355.

MarketsAndMarkets (2015) mHealth Solutions Market: Connected Devices (Blood Pressure Monitor, Glucose Meter, Pulse Oximeter), Apps (Weight Loss, Women's Health, Personal Health Record, \& Medication), Services (Remote Monitoring, Consultation, Prevention) - Global Forecast to 2020. Summary available at: www.marketsandmarkets.com/PressReleases/ mhealth-apps-and-solutions.asp (accessed 31 May 2017).

Meißner S (2016) Selbstoptimierung durch Quantified Self? Selbstvermessung als Möglichkeit von Selbststeigerung, Selbsteffektivierung und Selbstbegrenzung. In: Selke S (ed.) Lifelogging: Digitale Selbstvermessung und Lebensporotokollierung zwischen disruptiver Technologie und kulturellem Wandel. Wiesbaden: Springer.

Milani RV et al. (2016) The role of technology in chronic disease care. Progress in Cardiovascular Diseases 58(6): 579-583. 
Missomelius P (2016) Das digitale Selbst - Data Doubles der Selbstvermessung. In: Selke $\mathrm{S}$ (ed.) Lifelogging: Digitale Selbstvermessung und Lebensporotokollierung zwischen disruptiver Technologie und kulturellem Wandel. Wiesbaden: Springer.

Mol A (2002) The Body Multiple: Ontology in Medical Practice. Durham/ London: Duke University Press.

Moore PV (2017) The Quantified Self in Precarity: Work, Technology and What Counts. New York: Routledge.

Moore PV (2018) Tracking affective labour for agility in the quantified workplace. Body \& Society 24(3): 39-67.

Munson SA et al. (2014) Gamification and health. In: Walz SP and Deterding S (eds) The Gameful World: Approaches, Issues, Applications. Cambridge, MA: MIT Press.

National Business Group on Health (2016) NBGH press release: Employers Invest in Technology to Promote Employee Wellbeing though Measuring Effectiveness Proves Challenging. Available at: www.businessgrouphealth. org/news/nbgh-news/press-releases/press-release-details/?ID=273 (accessed 16 August 2017).

National Business Group on Health/Xerox Human Resources Services (2016) 2016 Emerging Technology to Promote Employee Wellbeing. National Business Group on Health/Xerox Human Resources Services.

New York Daily News (2015) 'Lifestyle' diseases linked to unhealthy habits kill millions of people prematurely: WHO. Available at: www.nydailynews.com/ life-style/health/lifestyle-diseases-kill-millions-prematurely-article-1.2083946 (accessed 31 May 2017).

Office of the Privacy Commissioner of Canada (2014) Wearable Computing: Challenges and Opportunities for Privacy Protection. Gatineau: Office of the Privacy Commissioner of Canada.

Ojakangas M (2005) Impossible dialogue on bio-power: Agamben and Foucault. Foucault Studies (2): 5-28.

Philo C (2000) The birth of the clinic: An unknown work of medical geography. Area 32(1): 11-20.

Pink S and Fors V (2017) Being in a mediated world: Self-tracking and the mindbody environment. Cultural Geographies 24(3): 375-388.

PricewaterhouseCoopers (2015) Media Trend Outlook - Wearables: Die tragbare Zukunft kommt näher. Germany: PricewaterhouseCoopers AG.

Pritz SM (2016) Zur digitalen Selbstvermessung der Gefühle. In: Selke S (ed.) Lifelogging: Digitale Selbstvermessung und Lebensporotokollierung zwischen disruptiver Technologie und kulturellem Wandel. Wiesbaden: Springer.

Rabinow P (1992) Artificiality and enlightenment: From sociobiology to biosociality. In: Crary J and Kwinter S (eds) Incorporations. New York: Zone Books.

Rabinow P and Rose N (2006) Biopower today. BioSocieties 1(2): 195-217.

Research2Guidance (2016) mHealth App Developer Economics 2016: The Current Status and Trends of the mHealth App Market. Berlin: Reseach2Guidance.

Rose N (2001) The politics of life itself. Theory, Culture \& Society 18(6): 1-30. Rose N (2004 [1999]) Powers of Freedom: Reframing Political Thought. Cambridge: Cambridge University Press. 
Rose N (2007) The Politics of Life Itself: Biomedicine, Power, and Subjectivity in the Twenty-First Century. Princeton: Princeton University Press.

Rose N and Abi-Rached JM (2013) Neuro: The New Brain Sciences and the Management of the Mind. Princeton: Princeton University Press.

Ruckenstein M (2014) Visualized and interacted life: Personal analytics and engagements with data doubles. Societies 4(1): 68-84.

Ruckenstein M and Schüll DN (2017) The datafication of health. Annual Review of Anthropology 46(1): 261-278.

Ruffino P (2016) Games to live with. Digital Culture \& Society 2(1): 153-159.

Sanders R (2017) Self-tracking in the digital era: Biopower, patriarchy, and the new biometric body projects. Body \& Society 23(1): 36-63.

Schollas S (2016) 'Game of the World': Self-Tracking und Gamification als Mittel der Kundenbindung und des Marketings. In: Duttweiler $\mathrm{S}$ et al. (eds) Leben nach Zahlen: Self-Tracking als Optimierungsprojekt? Bielefeld: Transcript.

Schrape N (2014) Gamification and governmentality. In: Fuchs M et al. (eds) Rethinking Gamification. Lüneburg: Meson Press.

Schröder S (2015) Digital Insurance and Mobility. Available at: www.ivk.unikoeln.de/sites/versicherung_institut/docments/pdf/VW_2015_11_09_ DigitalInsurance_Schroeder_Vortrag.pdf (accessed 31 May $201 \overline{7}$ ).

Schüll ND (2014 [2012]) Addiction by Design: Machine Gambling in Las Vegas. Princeton: Princeton University Press.

Schüll ND (2016) Data for life: Wearable technology and the design of self-care. BioSocieties 11(3): 317-333.

Sharon T (2017) Self-tracking for health and the quantified self: Re-articulating autonomy, solidarity, and authenticity in an age of personalized healthcare. Philosophy \& Technology 30(1): 93-121.

Shusterman R (2014) Somaesthetics. In: Soegaard M and Dam RF (eds) The Encyclopedia of Human-Computer Interaction. Available at: www.interactiondesign.org/literature/book/the-encyclopedia-of-human-computer-interaction2nd-ed/somaesthetics (accessed 24 August 2017).

Stark D (2009) Heterarchy: The organization of dissonance. In: Stark D (ed.) The Sense of Dissonance: Accounts of Worth in Economic Life. Princeton: Princeton University Press.

Steinmann M (2017) Der Arzt wird verstärkt zum Moderator einer Krankheitsgeschichte. Neue Zürcher Zeitung, 22 February. Available at: www.nzz.ch/marktplaetze/sponsored-content-serie-digitalisierung-fuermckinsey/sponsored-content-serie-digitalisierung-fuer-mckinsey-8-den-digitalen-patienten-verstehen-ld.146613 (accessed 14 July 2017).

Stemmer P (1998) Tugend: Antike. In: Ritter J and Gründer K (eds) Historisches Wörterbuch der Philosophie, Bd. 10. Darmstadt: Wissenschaftliche Buchgesellschaft.

Swan M (2012) Health 2050: The realization of personalized medicine through crowdsourcing, the quantified self, and the participatory biocitizen. Journal of Personalized Medicine 2(3): 93-118.

Terry NP (2015) Mobile health: Assessing the barriers. Chest 147(5): 1429-1434. Thaler RH and Sunstein CR (2008) Nudge: Improving Decisions About Health, Wealth, and Happiness. New Haven/London: Yale University Press. 
Tudor-Locke C et al. (2008) Revisiting 'how many steps are enough?'. Medicine \& Science in Sports \& Exercise 40(7 Suppl): 537-543.

Tudor-Locke $\mathrm{C}$ et al. (2011) How many steps/day are enough? For adults. International Journal of Behavioral Nutrition and Physical Activity 8(79): 1-17.

Waldby C (2000) The Visible Human Project: Informatic Bodies and Posthuman Medicine. New York: Routledge.

Waldby C and Mitchell R (2006) Tissue Economies: Blood, Organs, and Cell Lines in Late Capitalism. Durham: Duke University Press.

Wehling P (2011) Biology, citizenship and the government of biomedicine: Exploring the concept of biological citizenship. In: Bröckling U et al. (eds) Governmentality: Current Issues and Future Challenges. New York: Routledge.

Whitson JR (2014) Foucault's fitbit: Governance and gamification. In: Walz SP and Deterding S (eds) The Gameful World: Approaches, Issues, Applications. Cambridge, MA: MIT Press.

World Health Organization (2013) Global Action Plan for the Prevention and Control of Noncommunicable Diseases 2013-2020. Geneva: WHO.

World Health Organization (2014) Global Status Report on Noncommunicable Diseases 2014. Geneva: WHO.

World Health Organization (2015) Noncommunicable Diseases Progress Monitor 2015. Geneva: WHO.

Peter Lindner is Professor of Economic Geography at Goethe University, Frankfurt am Main. His research interests focus on globalization and marketization studies as well as on the new governmentality of behavioural economics, 'smart' choice architecture (nudging), and sensorsoftware technologies. 